\title{
Advances in the genetics of schizophrenia: will high-risk copy number variants be useful in clinical genetics or diagnostics? David A Collier ${ }^{1}$, Evangelos Vassos ${ }^{1,2}$, Simon Holden ${ }^{3}$, Christine Patch ${ }^{3,4}$, Philip McGuire ${ }^{2}$ and Cathryn Lewis ${ }^{1,3}$
}

Addresses: ${ }^{1}$ Medical Research Council, Social, Genetic and Developmental Psychiatry Centre, Institute of Psychiatry, King's College, De Crespigny Park, Denmark Hill, London SE5 8AF, UK; ${ }^{2}$ Division of Psychological Medicine and Psychiatry, Institute of Psychiatry, King's College, De Crespigny Park, Denmark Hill, London SE5 8AF, UK; ${ }^{3}$ Department of Clinical Genetics Guy's \& St Thomas' NHS Foundation Trust, Great Maze Pond, London SE1 9RT, UK; ${ }^{4}$ Biomedical Research Centre, Guy's and St Thomas' NHS Foundation Trust and King's College, Great Maze Pond, London SE1 9RT, UK

*Corresponding author: David A Collier (d.collier@iop.kcl.ac.uk)

FI000 Medicine Reports 2009, I:6I (doi:10.3410/MI-6I)

The electronic version of this article is the complete one and can be found at: http://FI000.com/Reports/Medicine/content/I/6I

\begin{abstract}
Schizophrenia is a highly heritable, common mental illness, affecting $I \%$ of the population worldwide. It is currently diagnosed using exclusive clinical criteria, and at present there are no genetic tests to facilitate this process. There are also no reliable means to predict who will develop the disease in later life. Genetic counselling uses crude estimates of risk based on family history, as the strongest predictive factor is having an affected first-degree relative. It has recently become apparent that large de novo deletions in the genome (copy number variants, or CNVs) can increase risk of the disease by tenfold or more. The purpose of this report is to assess whether these 'high risk' pathogenic CNVs might be useful in a clinical genetic or diagnostic setting. Routine use of laboratory techniques such as comparative genome hybridisation will reveal these de novo CNVs in standard investigative procedures for referrals to clinical genetics. The lack of disease specificity of CNVs presents problems for their use in diagnosis at present. Currently, there is also insufficient evidence in relation to schizophrenia to suggest that clear clinical benefit would be gained from learning one's genetic status pre-symptomatically. However, this is likely to change rapidly in the near future as knowledge of the genetic and environmental basis of schizophrenia accrues and increasingly effective measures for early intervention and risk reduction are developed.
\end{abstract}

\section{Introduction and context}

Schizophrenia is a severe mental illness, with heritability estimated at over $80 \%$ and onset in adolescence or early adulthood [1]. Its aetiology is complex and multifactorial, involving interaction between multiple genetic and environmental factors, and therefore the identification of the underlying genetic basis has proven difficult. The working hypothesis for genetic influences on schizophrenia has been the 'common disease, common allele' model, in which the illness is caused by combinations of genetic variants which are frequent in the populations (for example, a risk allele frequency of more than 5\%), each contributing a modest effect. Over 1,000 genetic association studies have been published, with largely inconsistent results, but a recent meta-analysis has identified 16 genes with nominally significant effects and an average pooled odds ratio of 1.23 [2]. Genomewide approaches examining common single-nucleotide polymorphisms (SNPs) for association with schizophrenia are also beginning to yield results [for example, an SNP in the ZNF804A gene, which has a relative risk of about 1.1] [3]. These variants have extremely low penetrance; that is, the vast majority of those who carry them do not develop schizophrenia. Because of this, 
common variants have poor predictive power and limited utility in clinical genetics, at least in isolation.

The alternative 'rare variant' model proposes that genetic variants predisposing to schizophrenia are penetrant mutations, which are of recent origin and individually rare, even specific to single cases or families [4]. A severe mutation such as a deleterious amino acid change on a protein or a deletion in any of the genes involved in neurodevelopmental pathways may lead to a psychopathological phenotype; variable expression or penetrance may arise by genetic or epigenetic 'second hits' or simply by chance [5]. One such mutation is a copy number variant (CNV) on chromosome 22 which deletes 1.5 to 3 million base pairs of DNA and causes 22q11.2 deletion syndrome (velocardiofacial syndrome, or VCFS). This is a well-established risk factor for schizophrenia and other neuropsychiatric phenotypes such as autism spectrum disorders; at least $25 \%$ of subjects with a deletion develop psychosis [6]. As discussed below, there is evidence that CNVs such as 22q11.2 deletion may play an important role in the aetiology of schizophrenia [7].

Thus, it is possible to conceptualise the genetics of schizophrenia as a disorder made up of genetic risk conferred by three types of variants: common low-risk sequence variants such as SNPs which increase risk by 1.1- to 2-fold, rare CNVs such as the VCFS deletion which increase the risk of schizophrenia by 3 - to 50 -fold, and rare deleterious sequence variants such as non-synonymous SNPs. Current commercially available microarrays cannot easily detect association with rare SNP variants [8] and therefore large-scale DNA sequencing is required for their discovery, so less is known about the role of these variants in complex disorders such as schizophrenia. It is possible to speculate that $10-20 \%$ of genetic risk is from $\mathrm{CNVs}$, a similar percentage from rare sequence variants, and the remainder from many common low-risk polymorphisms [9]. A better understanding of the genetic (and indeed environmental) basis of schizophrenia may facilitate both risk prediction and diagnosis.

It is theoretically possible to use these various types of genetic susceptibility variants to predict risk. Using Crohn's disease (CD) as a model of a common complex disorder, Lewis et al. [10] developed methods to estimate disease risks using both genetic and environmental risk factors. They found that high absolute risks of $\mathrm{CD}$ can be obtained by incorporating information on smoking, family history and NOD2 gene mutations. Additional information on genetic risk can be incorporated into this model as it arises to improve risk prediction. This approach should have utility in the clinical setting for both genetic counselling and behavioural modification to reduce risk (for example, smoking cessation).

\section{Recent advances}

In addition to 22q11.2 deletions, high-risk newly occurring deletions and duplications of DNA (CNVs) have recently emerged as genomic risk factors for common brain disorders, including schizophrenia, autism and mental retardation $[7,11,12]$. This involves an excess of rare de novo CNVs across the genome as a whole [5,13], which at an individual level probably represents the damaging effect of very large mutations on brain function [14]. Some of these may be 'private' pathogenic mutations possibly unique to a single individual. Others appear to be recurrent mutations at specific sites, such as on chromosomes 1q21.1, 15q11.2, $15 \mathrm{q} 13.3$ and the neurexin 1 (NRXN1) gene at 2p16.3 [14-18]. These CNVs are not specific to any particular psychiatric diagnosis and can give rise to a range of phenotypes, from autism to epilepsy [12,19-22].

These pathogenic CNVs tend to be rare in the population: deletions at 1q21.1 and 15q13.3 occur in about $1 / 500$ patients with schizophrenia compared with $1 / 5,000$ controls without neuropsychiatric illness $[15,16]$. In idiopathic generalized epilepsy, however, deletions at $15 \mathrm{q} 13.3$ occur in as many as $1 / 100$ of cases [21], whereas the 15q11.2 deletion occurs in about $1 / 200$ patients with schizophrenia [15]. These pathogenic CNVs have a high odds ratio for risk, at around 3 - to 10-fold increased risk, in contrast to common variants, which show odds ratios between 1 and 2 . Thus, the penetrance of the pathogenic CNVs discovered so far is intermediate between common variants and the highrisk variants associated with syndromes commonly used in a clinical genetic setting, at between 2 and $9 \%$ for schizophrenia, compared with $11-55 \%$ for VCFS deletions [Vassos et al., personal communication]. Given that these variants can give rise to multiple neuropsychiatric phenotypes, the overall penetrance for any disorder is likely to be considerably higher; for example, although the penetrance for 15q13.3 deletions in schizophrenia is 6-9\%, penetrance for idiopathic generalized epilepsy is much higher [20, Vassos et al., personal communication].

\section{Implications for clinical practice}

These findings will impact on clinical practice in two areas, diagnosis and risk assessment (genetic counselling). At present, schizophrenia is diagnosed using clinical criteria, which means that because of the low yield of clinically relevant variants (such as the 22q11.2 VCFS deletion) patients with schizophrenia are not commonly assessed by genetic testing. However, this 
picture is likely to change as further CNVs are identified and their clinical relevance becomes more widely understood. In addition, children who show idiopathic developmental delay (for example, intellectual disability, language delay or both) or 'chromosomal' phenotype (that is, developmental delay in association with growth retardation, facial dysmorphism and minor or major congenital abnormalities) are usually assessed in a clinical genetic setting. Here, conventional cytogenetic analysis is being replaced by CGH and other DNA-based methods because they have the potential to detect the majority of microscopic and submicroscopic chromosomal abnormalities [23]. This will inevitably lead to the identification of children who carry CNVs associated with the later development of schizophrenia and other paediatric or adult neuropsychiatric phenotypes, which raises ethical and practical issues.

In terms of diagnostics, the observation that CNVs are not disorder-specific but cross diagnostic boundaries presents difficulties, as these pleiotropic effects challenge current psychiatric diagnosis and current classification systems [24]. One option is that these disorders be considered separate syndromes (for example, '2p16.3 deletion syndrome' or 'NRXN1 deletion syndrome'). However, patients with schizophrenia who have pathogenic CNVs are not obviously unusual in their phenotype [17] and to classify them as having separate syndromes, given that the penetrance of CNV mutations is incomplete and that other factors may be involved in the disease, may not make sense. Only when there is a fuller understanding of the role of both CNVs and common and rare sequence variants (for example, SNPs) in susceptibility, together with an understanding of the genetic and environmental factors which modify penetrance and phenotype, may it be possible to diagnose phenotype on the basis of genetics.

In terms of genetic counselling and risk assessment, genetic and environmental factor research is likely to lead to validated clinical tests to assess psychosis risk in the long term, which will gradually replace the current family history-based assessment of risk $[25,26]$. Genetic counselling is likely to have an important role in bridging research and clinical practice in psychiatry. While there are controversies relating to predictive testing in mental illness that cannot be dismissed $[27,28]$, there may be considerable benefits; these include addressing misconceptions about the illness, reducing guilt and stigma, and introducing adaptive strategies and nondirective support for decision making, resulting in improvements in quality of life, compliance with medication, and reduction in risky behaviours [29]. In a recent study of schizophrenia [30], no affected individuals and only 1 in 20 relatives had received genetic counselling. However, over $40 \%$ indicated that their family planning decisions were influenced by having schizophrenia in their family, and over $70 \%$ thought genetic counselling would be useful.

However, there are considerable ethical issues to be considered, especially as schizophrenia commonly occurs during adolescence or early adulthood. In some cases, schizophrenia may be preceded by idiopathic developmental delay in childhood [31] and therefore the implications of genetic testing of children must be considered. Since, unlike in Mendelian disorders, no definite genetic factors that predict the development of schizophrenia have been established so far and since there are considerable ethical and societal issues relating to mental illness and prenatal diagnosis, prenatal testing is not appropriate in this context.

Questions of ethics most commonly centre on whether there is a clear clinical benefit to be gained from learning the genetic status of the patient, before symptoms of schizophrenia or another disorder develop. Genetic testing is most likely to occur in high-risk groups, such as children with idiopathic 'non-chromosomal' intellectual and motor developmental delay $[31,32]$ who might present to clinical genetic services, those at high genetic risk because of family history of the disease (about 10\% risk) [33], or people who have prodromal symptoms (30\% risk of conversion to full-blown psychosis) [34]. Delays and/or abnormalities in motor and language development, intellectual and cognitive impairment, disturbances in emotional and behavioural functioning as well as social and interpersonal maladjustment are all childhood antecedents of schizophrenia [32] which might trigger genetic screening and the identification of pathogenic CNVs; perhaps 5\% of children referred to clinical genetic testing for these reasons will later develop schizophrenia.

Genetic testing may be beneficial in a clinical genetic context for families with a history of schizophrenia. In these families, the identification of a case who has an isolated de novo $\mathrm{CNV}$ not present in the parents would indicate a reduction in risk for other family members, as the de novo mutation is a rare event and unlikely to re-occur. On the other hand, if a parent carried the $\mathrm{CNV}$, risk would be higher as it could be passed on to offspring. Family history of psychosis may also have a significant impact on penetrance of CNVs, as is seen in haemochromatosis gene (HFE)-related haemochromatosis. In a scenario in which an unaffected parent is found to carry the mutation, the risk of disease to future offspring is modulated by family history; there is an 
approximately $1 \%$ risk of clinical disease in a female offspring who is homozygous for $\mathrm{C} 282 \mathrm{Y}$ mutation and has no family history compared with $10 \%$ if there is a closely related affected relative, with the same HFE haplotype in both cases. This mediation of the penetrance appears to result from concomitant mutations in other iron master genes [35]. Thus, in a family with a history of schizophrenia and a pathogenic CNV, the risk to offspring of a carrier of a pathogenic CNV may be substantially higher than indicated by the population prevalence.

Predictive testing might be conceived as useful if it were able to stratify risk and act as an 'early warning' system for intervention; this could be used in a preventative sense in order, for example, to reduce harmful behaviour in those at high risk or to attempt to reduce the duration of untreated psychosis (DUP), which averages 1-2 years for people who develop schizophrenia [36]. A reduction of DUP may confer clinical benefits [37]. In addition, better predictive tools in certain high-risk groups, such as prodromal patients in whom antipsychotic medication is being trialled to prevent onset of psychosis or improve course [38], have the potential to better target medications and reduce their unnecessary use. However, the benefits of drug treatment in prodromal psychosis are as yet unclear, and in any case, the implications of a pathogenic de novo $\mathrm{CNV}$ for progression to full-blown psychosis are at present unknown, and this will need careful assessment given their low penetrance. Thus, while these are potential areas of clinical use, there is little good evidence that, at present, clear clinical benefit would be gained from learning the genetic status of the patient. Despite this, commercial genetic testing companies are marketing tests directly to consumers based on discoveries from genome-wide association studies. This may carry some benefits (for example, in relation to lung cancer or obesity risk, in which lifestyle changes such as smoking cessation or exercise are very effective). However, in the absence of evidence of clinical validity or utility this may be premature, especially for diseases such as schizophrenia that are severe or carry stigma, and has led to calls for greater discussion of the policy implications $[39,40]$.

The complex ethical issues, coupled with the potential for adverse psychological effects that might accompany genetic testing and the risk of stigmatisation of individuals at 'high risk', need to be weighted against the potential benefits (genetic counselling and psychoeducation of patients and relatives, early detection of illness and implementation of treatment, and minimisation of risk behaviours) $[26,27,29,30]$. Knowledge of these dilemmas is a first step to resolving them, something that the medical profession will need to attend to in the near term [41].

\section{Abbreviations}

$\mathrm{CD}$, Crohn's disease; CGH, comparative genome hybridisation; $\mathrm{CNV}$, copy number variant; DUP, duration of untreated psychosis; HFE, haemochromatosis gene; NOD2, nucleotide-binding oligomerization domain containing 2; NRXN1, neurexin 1; SNP, single-nucleotide polymorphism; VCFS, velocardiofacial syndrome.

\section{Competing interests}

The authors declare that they have no competing interests.

\section{Acknowledgements}

The authors were supported by EU grant LSHM-CT2006-037761 (Project SGENE) and the Guy's and St Thomas' Charity (http://www.gsttcharity.org.uk) and the Department of Health via the National Institute for Health Research (NIHR) comprehensive Biomedical Research Centre award to Guy's \& St Thomas' NHS Foundation Trust in partnership with King's College London and King's College Hospital NHS Foundation Trust.

\section{References}

I. Cardno AG, Gottesman II: Twin studies of schizophrenia: from bow-and-arrow concordances to star wars $M x$ and functional genomics. Am J Med Genet 2000, 97:12-7.

2. Allen NC, Bagade S, McQueen MB, loannidis JP, Kavvoura FK, Khoury MJ, Tanzi RE, Bertram L: Systematic meta-analyses and field synopsis of genetic association studies in schizophrenia: the SzGene database. Nat Genet 2008, 40:827-34.

FI000 Factor 3.0 Recommended

Evaluated by Victor Reus 03 Jul 2008

3. O'Donovan MC, Craddock N, Norton N, Williams $H$, Peirce T, Moskvina V, Nikolov I, Hamshere M, Carroll L, Georgieva L, Dwyer S, Holmans P, Marchini JL, Spencer CC, Howie B, Leung HT, Hartmann AM, Möller HJ, Morris DW, Shi Y, Feng G, Hoffmann P, Propping $P$, Vasilescu C, Maier W, Rietschel M, Zammit S, Schumacher J, Quinn EM, Schulze TG et al.: Identification of loci associated with schizophrenia by genome-wide association and follow-up. Nat Genet 2008, 40:1053-5.

4. lyengar SK, Elston RC: The genetic basis of complex traits: rare variants or 'common gene, common disease'? Methods Mol Biol 2007, 376:7I-84.

5. Walsh T, McClellan JM, McCarthy SE, Addington AM, Pierce SB, Cooper GM, Nord AS, Kusenda M, Malhotra D, Bhandari A, Stray SM, Rippey CF, Roccanova P, Makarov V, Lakshmi B, Findling RL, Sikich L, Stromberg T, Merriman B, Gogtay N, Butler P, Eckstrand K, Noory L, Gochman P, Long R, Chen Z, Davis S, Baker C, Eichler EE, Meltzer PS et al.: Rare structural variants disrupt multiple genes in neurodevelopmental pathways in schizophrenia. Science 2008, 320:539-43.

FI000 Factor 8.I Must Read

Evaluated by Karoly Mirnics 17 Apr 2008, Steven Potkin 17 Jun 2008, Rudolf Uher 29 Aug 2008

6. Bassett AS, Marshall CR, Lionel AC, Chow EW, Scherer SW: Copy number variations and risk for schizophrenia in $22 \mathrm{ql} I .2$ deletion syndrome. Hum Mol Genet 2008, I 7:4045-53. 
7. St Clair D: Copy number variation and schizophrenia. Schizophr Bull 2009, 35:9-12.

8. Barrett JC, Cardon LR: Evaluating coverage of genome-wide association studies. Nat Genet 2006, 38:659-62.

FI000 Factor 6.0 Must Read

Evaluated by Pui-Yan Kwok 28 Sep 2006

9. Purcell S: Varieties of genetic variation in neuropsychiatric disease. Presented at the XVIth World Congress on Psychiatric Genetics; 14 October 2008; Osaka, Japan.

10. Lewis CM, Whitwell SC, Forbes A, Sanderson J, Mathew CG, Marteau TM: Estimating risks of common complex diseases across genetic and environmental factors: the example of Crohn disease. J Med Genet 2007, 44:689-94.

II. Sebat J, Lakshmi B, Malhotra D, Troge J, Lese-Martin C, Walsh T, Yamrom B, Yoon S, Krasnitz A, Kendall J, Leotta A, Pai D, Zhang R, Lee YH, Hicks J, Spence SJ, Lee AT, Puura K, Lehtimäki T, Ledbetter D, Gregersen PK, Bregman J, Sutcliffe JS, Jobanputra V, Chung W, Warburton D, King MC, Skuse D, Geschwind DH, Gilliam TC et al:: Strong association of de novo copy number mutations with autism. Science 2007, 316:445-9.

FI000 Factor 3.0 Recommended

Evaluated by Tony Charman 27 Mar 2007

12. Mefford HC, Sharp AJ, Baker C, Itsara A, Jiang Z, Buysse K, Huang S, Maloney VK, Crolla JA, Baralle D, Collins A, Mercer C, Norga K, de Ravel $T$, Devriendt $K$, Bongers $E M$, de Leeuw $N$, Reardon $W$, Gimelli S, Bena F, Hennekam RC, Male A, Gaunt L, Clayton-Smith J, Simonic I, Park SM, Mehta SG, Nik-Zainal S, Woods CG, Firth HV et al.: Recurrent rearrangements of chromosome Iq2I.I and variable pediatric phenotypes. $N$ Engl J Med 2008, 359:1685-99.

13. Xu B, Roos JL, Levy S, van Rensburg EJ, Gogos JA, Karayiorgou M: Strong association of de novo copy number mutations with sporadic schizophrenia. Nat Genet 2008, 40:880-5.

FI000 Factor 3.0 Recommended

Evaluated by Francine Benes 10 Jul 2008

14. Kirov G, Grozeva D, Norton N, Ivanov D, Mantripragada KK, Holmans P; International Schizophrenia Consortium; the Wellcome Trust Case Control Consortium, Craddock N, Owen MJ, O'Donovan MC: Support for the involvement of large copy number variants in the pathogenesis of schizophrenia. Hum Mol Genet 2009, I8:1497-503.

15. Stefansson $H$, Rujescu $D$, Cichon $S$, Pietiläinen $O P$, Ingason $A$, Steinberg $S$, Fossdal R, Sigurdsson E, Sigmundsson T, BuizerVoskamp JE, Hansen T, Jakobsen KD, Muglia P, Francks C, Matthews PM, Gylfason A, Halldorsson BV, Gudbjartsson D, Thorgeirsson TE, Sigurdsson A, Jonasdottir A, Jonasdottir A, Bjornsson A, Mattiasdottir S, Blondal T, Haraldsson $M$, Magnusdottir BB, Giegling I, Möller HJ, Hartmann A et al:: Large recurrent microdeletions associated with schizophrenia. Nature 2008, 455:232-6.

FI000 Factor 6.0 Must Read

Evaluated by Karoly Mirnics 08 Aug 2008

16. International Schizophrenia Consortium: Rare chromosomal deletions and duplications increase risk of schizophrenia. Nature 2008, 455:237-4I.

17. Rujescu D, Ingason A, Cichon S, Pietiläinen OP, Barnes $M R$, Toulopoulou T, Picchioni M, Vassos E, Ettinger U, Bramon E, Murray R, Ruggeri M, Tosato S, Bonetto C, Steinberg S, Sigurdsson E, Sigmundsson T, Petursson $\mathrm{H}$, Gylfason A, Olason PI, Hardarsson G, Jonsdottir GA, Gustafsson O, Fossdal R, Giegling I, Möller HJ, Hartmann AM, Hoffmann P, Crombie C, Fraser G et al:: Disruption of the neurexin I gene is associated with schizophrenia. Hum Mol Genet 2009, 18:988-96.

18. Vrijenhoek T, Buizer-Voskamp JE, van der Stelt I, Strengman E; Genetic Risk and Outcome in Psychosis (GROUP) Consortium, Sabatti C, Geurts van Kessel A, Brunner HG, Ophoff RA, Veltman JA: Recurrent CNVs disrupt three candidate genes in schizophrenia patients. Am J Hum Genet 2008, 83:504-10.
19. Sharp AJ, Mefford HC, Li K, Baker C, Skinner C, Stevenson RE, Schroer RJ, Novara F, De Gregori M, Ciccone R, Broomer A, Casuga I, Wang Y, Xiao C, Barbacioru C, Gimelli G, Bernardina BD, Torniero C, Giorda R, Regan R, Murday V, Mansour S, Fichera M, Castiglia L, Failla P, Ventura M, Jiang Z, Cooper GM, Knight SJ, Romano $C$ et al:: A recurrent I5q13.3 microdeletion syndrome associated with mental retardation and seizures. Nat Genet 2008, 40:322-8.

20. Pagnamenta AT, Wing K, Akha ES, Knight SJ, Bölte S, Schmötzer G, Duketis E, Poustka F, Klauck SM, Poustka A, Ragoussis J, Bailey AJ, Monaco AP: A I 5q I3.3 microdeletion segregating with autism. Eur J Hum Genet 2008, 17:687-92.

21. Helbig I, Mefford HC, Sharp AJ, Guipponi M, Fichera M, Franke A, Muhle H, de Kovel C, Baker C, von Spiczak S, Kron KL, Steinich I, Kleefuss-Lie AA, Leu C, Gaus V, Schmitz B, Klein KM, Reif PS, Rosenow F, Weber Y, Lerche H, Zimprich F, Urak L, Fuchs K, Feucht M, Genton P, Thomas P, Visscher F, de Haan G], Møller RS et al.: I5qI3.3 microdeletions increase risk of idiopathic generalized epilepsy. Nat Genet 2009, 41:160-2.

FI000 Factor 6.0 Must Read Evaluated by Christopher Gillberg 20 Jan 2009

22. Miller DT, Shen Y, Weiss LA, Korn J, Anselm I, Bridgemohan C, Cox GF, Dickinson H, Gentile J, Harris DJ, Hegde V, Hundley R, Khwaja O, Kothare S, Luedke C, Nasir R, Poduri A, Prasad K, Raffalli P, Reinhard A, Smith SE, Sobeih M, Soul J, Stoler J, Takeoka M, Tan WH, Thakuria J, Wolff P, Yusupov R, Gusella JF et al.: Microdeletion/duplication at I5qI3.2q 13.3 among individuals with features of autism and other neuropsychiatirc disorders. J Med Genet 2009, 46:242-8.

23. Bejjani BA, Shaffer LG: Clinical utility of contemporary molecular cytogenetics. Annu Rev Genomics Hum Genet 2008, 9:7I-86.

24. O'Donovan MC, Kirov G, Owen MJ: Phenotypic variations on the theme of CNVs. Nat Genet 2008, 40:1392-3.

25. Tsuang MT: Genetic counseling for psychiatric patients and their families. Am J Psychiatry 1978, 135:|465-75.

26. Finn CT, Smoller JW: Genetic counseling in psychiatry. Harv Rev Psychiatry 2006, 14:109-21.

27. Austin JC, Smith GN, Honer WG: The genomic era and perceptions of psychotic disorders: genetic risk estimation, associations with reproductive decisions and views about predictive testing. Am J Med Genet B Neuropsychiatr Genet 2006, I4I B:926-8.

28. Kuehn BM: Prenatal genome testing sparks debate. JAMA 2008, 300:1637-9.

29. Austin JC, Honer WG: The genomic era and serious mental illness: a potential application for psychiatric genetic counseling. Psychiatr Serv 2007, 58:254-6I.

30. Lyus VL: The importance of genetic counseling for individuals with schizophrenia and their relatives: potential clients' opinions and experiences. Am J Med Genet B Neuropsychiatr Genet 2007, I44B:10|4-2I.

31. Jones P, Rodgers B, Murray R, Marmot M: Child development risk factors for adult schizophrenia in the British 1946 birth cohort. Lancet 1994, 344: 1398-402.

32. Laurens KR, Hodgins S, Maughan B, Murray RM, Rutter ML, Taylor EA: Community screening for psychotic-like experiences and other putative antecedents of schizophrenia in children aged 9-12 years. Schizophr Res 2007, 90:130-46.

33. Cardno AG, Thomas K, McGuffin P: Clinical variables and genetic loading for schizophrenia: analysis of published Danish adoption study data. Schizophr Bull 2002, 28:393-9.

34. Yung AR, Yuen HP, Berger G, Francey S, Hung TC, Nelson B, Phillips $L$, McGorry $P$ : Declining transition rate in ultra high risk (prodromal) services: dilution or reduction of risk? Schizophr Bull 2007, 33:673-8I.

35. Le Gac G, Scotet V, Ka C, Gourlaouen I, Bryckaert L, Jacolot S, Mura $C$, Férec $C$ : The recently identified type $2 A$ juvenile haemochromatosis gene $(\mathrm{HJV})$, a second candidate modifier 
of the C282Y homozygous phenotype. Hum Mol Genet 2004, 13:1913-8.

36. McGlashan TH: Duration of untreated psychosis in first-episode schizophrenia: marker or determinant of course? Biol Psychiatry 1999, 46:899-907.

37. Melle I, Larsen TK, Haahr U, Friis S, Johannesen JO, Opjordsmoen S, Rund BR, Simonsen E, Vaglum P, McGlashan T: Prevention of negative symptom psychopathologies in first-episode schizophrenia: two-year effects of reducing the duration of untreated psychosis. Arch Gen Psychiatry 2008, 65:634-40.

FI000 Factor 4.8 Must Read

Evaluated by John Nurnberger 15 Jul 2008, Alfredo Carlo Altamura 21 Jul 2009
38. Hawkins KA, Keefe RS, Christensen BK, Addington J, Woods SW, Callahan J, Zipursky RB, Perkins DO, Tohen M, Breier A, McGlashan TH: Neuropsychological course in the prodrome and first episode of psychosis: findings from the PRIME North America Double Blind Treatment Study. Schizophr Res 2008, 105:1-9.

39. Kuehn BM: Risks and benefits of direct-to-consumer genetic testing remain unclear. JAMA 2008, 300:1503-5.

40. Braff $D L$, Freedman R: Clinically responsible genetic testing in neuropsychiatric patients: a bridge too far and too soon. $A m$ Psychiatry 2008, 165:952-5.

41. Appelbaum PS: Ethical issues in psychiatric genetics. J Psychiatr Pract 2004, 10:343-5I. 